\title{
Whole grain intake of Australians estimated from a cross-sectional analysis of dietary intake data from the 2011-13 Australian Health Survey
}

\author{
Leanne M Galea ${ }^{1,2, *}$, Eleanor J Beck ${ }^{1,2}$, Yasmine C Probst ${ }^{1,2}$ and Chris J Cashman ${ }^{3}$ \\ ${ }^{1}$ School of Medicine, Faculty of Science Medicine and Health, University of Wollongong, Northfields Avenue, \\ Wollongong, NSW 2522, Australia: ${ }^{2}$ Illawarra Health and Medical Research Institute, Wollongong, NSW, \\ Australia: ${ }^{3}$ Sanitarium Health and Wellbeing, Berkeley Vale, NSW, Australia
}

Submitted 11 January 2017: Final revision received 31 March 2017: Accepted 25 April 2017: First published online 8 June 2017

\begin{abstract}
Objective: The Australian Dietary Guidelines recommend Australians choose mostly whole-grain and/or high-fibre varieties within the grains (cereal) foods category, with other groups specifying a whole grain Daily Target Intake of $48 \mathrm{~g}$ for Australians aged 9 years or above. The USA and UK report estimates of whole grain intake that are low and declining, and no comprehensive studies on whole grain intake in the Australian population are available. The present study aimed to determine national estimates of whole grain intake, compared with current recommendations.

Design: A recently updated whole grain database was applied to the most current population dietary intake data. Single $24 \mathrm{~h}$ dietary recall intake data were reviewed against age group, sex, relative to energy intake and whole grain recommendations.

Setting: Australia.

Subjects: Australians (2-85 years) participating in the 2011-13 Australian Health Survey ( $n$ 12 153).

Results: The median daily whole grain intake was $21 \mathrm{~g}$ for adults (19-85 years) and $17 \mathrm{~g}$ for children/adolescents (2-18 years), or 28 and $23 \mathrm{~g} / 10 \mathrm{MJ}$ per d, respectively. Approximately $30 \%$ of children/adolescents consumed no whole grains on the day of the survey. Whole grain intake was lowest for the age group $14-18$ years $(8.7 \mathrm{~g} / \mathrm{d})$. Of all participants aged $\geq 9$ years, $73 \%$ did not reach the recommended Daily Target Intake of $48 \mathrm{~g}$.

Conclusions: Whole grain intake in Australia is below recommendations in all age groups. Adolescents may be a key target for campaigns to increase whole grain consumption. This study provides the first quantification of absolute whole grain intake from all food sources in a national sample of Australians.
\end{abstract}

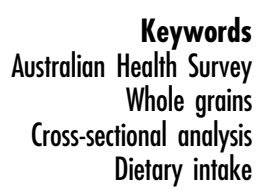

Epidemiological studies of adult populations have reported an inverse relationship between intake of whole grains and risk of chronic diseases, including $\mathrm{CVD}^{(1,2)}$, type 2 diabetes $^{(3)}$ and some cancers ${ }^{(4)}$. Whole grains may also have a role in weight management ${ }^{(5,6)}$. However, generally, whole grain consumption of any population has been difficult to study as the majority of intake data available do not contain quantified whole grain intake measures. Dietary guidelines developed globally, including the Australian Dietary Guidelines, recommend choosing mostly whole-grain and/or high-cerealfibre foods within the cereals food group ${ }^{(7)}$. Other groups promoting whole grain consumption encourage
Australians aged 9 years or above to meet a whole grain Daily Target Intake (DTI) of $48 \mathrm{~g}^{(8)}$.

A whole grain database has been expanded to include all whole-grain foods reported within the Nutrition and Physical Activity component of the Australian Health Survey $^{(9)}$, providing a useful tool to quantify whole grain intake. Secondary analysis of dietary intake data, involving the application of this whole grain database, provides a more in-depth understanding of both the amounts and patterns of consumption of whole grains to assist guidance of both nutrition education and food product development ${ }^{(10)}$. In addition, absolute amounts of whole grain intake at the food level help to account for biological 
interactions that might otherwise be lost in the analysis of individual nutrients ${ }^{(11)}$.

The aims of the present study were to determine: (i) national estimates of reported whole grain intake, compared with national guidelines (Australian Dietary Guidelines and DTI); and (ii) key dietary sources of whole grains within the Australian diet.

\section{Materials and methods}

\section{Data and study population}

A full description of methods for data collection in the Australian Health Survey has been reported by the Australian Bureau of Statistics ${ }^{(12)}$. In brief, the Australian Health Survey is a nationally representative cross-sectional survey conducted between 2011 and 2013. Within this broader survey, the National Nutrition and Physical Activity Survey (NNPAS) collected data on the nutrition and health status of individuals aged 2-85 years, based on a stratified multistage area sample of private dwellings, which are geographically and demographically representative of the Australian non-institutionalised population $^{(13)}$. The data set used for the analyses of the present study was from the Australian Bureau of Statistics' Confidentialised Unit Record Files obtained in the NNPAS.

\section{Dietary assessment}

Dietary intake data of the NNPAS were collected by trained interviewers using computer- and telephone-assisted $24 \mathrm{~h}$ dietary recalls, adapted using the Automated Multiple-Pass Method. Detailed descriptions of dietary interview methods, including a Food Model Booklet used by interviewers to assist in describing amounts of food and beverages consumed, are provided elsewhere ${ }^{(12)}$. Intake data were collected for one day for 12153 participants and a second recall was repeated with a sub-sample ( $n$ 7735).

\section{Estimation of whole grain intake}

Age categories for analysis were selected in line with Nutrient Reference Value age groupings ${ }^{(14)}$; hereafter referred to as children (2-18 years) and adults (19-85 years). Differences between mean whole grain intake on day 1 of the survey and the average of two days were determined using a paired-samples $t$ test. A statistically significant difference existed $(33.9$ and $33.6 \mathrm{~g} / \mathrm{d}$, respectively; $P=0.000$ ). The difference of $0.3 \mathrm{~g}$ whole grains between the mean values was not deemed clinically relevant and did not justify excluding the participants who did not provide two days of dietary intake data, hence data from day 1 of the survey were used.

Whole grains considered in the present study aligned with the Food Standards Australia New Zealand definition as the intact grain or the dehulled, ground, milled, cracked or flaked grain where the constituents - endosperm, germ and bran - are present in such proportions that represent the typical ratio of those fractions occurring in the whole cereal, and includes wholemeal ${ }^{,(15)}$.

The whole grain percentage of each food item identified as containing whole grains was calculated using a whole grain database ${ }^{(9)}$. In brief, from over 5700 food codes, 590 foods were identified as containing any whole grains, as a percentage of the fresh weight of food. Whole grain content was calculated through the adaptation of an existing whole grain database ${ }^{(16)}$, recipes and ingredient information, including input from nonprofit organisations and industry sources. Whole grain intake was calculated by multiplying the gram weight of all foods reported as containing whole grains, by the percentage of whole grains, avoiding the use of an arbitrary cut-off to define whole-grain foods. Foods were classified as core (non-discretionary) and discretionary using criteria within the Australian Dietary Guidelines ${ }^{(7)}$. Core cereal foods include mostly whole-grain and/or high-cereal-fibre varieties. This includes breads, cereals, rice, pasta, noodles, polenta, couscous, oats, quinoa and barley ${ }^{(7)}$. Within the context of cereal foods, discretionary foods include highly refined versions containing added fats and/or sugars such as biscuits, cakes, pastries, commercial burgers, pizza, fried foods and other savoury snacks ${ }^{(17)}$.

Intake was reviewed to determine the number of consumers meeting the DTI. Consumption was also reviewed within age groups, using food intake data and food group codes.

\section{Statistical analyses}

To account for differences in total dietary intake by age and sex, whole grain intake was adjusted for daily energy intake $(10 \mathrm{MJ} / \mathrm{d})$ as reported within single $24 \mathrm{~h}$ recalls ${ }^{(18)}$, providing a relative representation of whole grain density of the diet. Parametric tests were applied to the data. Differences between age groups and sex in meeting whole grain recommendations were assessed using $\chi^{2}$ analyses to compare associations between proportions. One-way ANOVA and Bonferroni post hoc tests were used to explore statistically significant differences in whole grain intake between age groups.

All statistical analyses used the statistical software package IBM SPSS Statistics version 21 (2009). Given the sample size of the data set, effect size was calculated using $\eta^{2}$, calculated as the sum of squares between groups divided by the total sum of squares. The strength of the effect was interpreted based on Cohen's criteria ${ }^{(19)}$.

\section{Results}

On the day of the survey, the median whole grain intake for children was $16.5 \mathrm{~g} / \mathrm{d}(22.7 \mathrm{~g} / 10 \mathrm{MJ}$ per d), range $8.7-21.2 \mathrm{~g} / \mathrm{d}$ across age groups. Median whole grain intake 
for adults was $21.2 \mathrm{~g} / \mathrm{d}(28.0 \mathrm{~g} / 10 \mathrm{MJ}$ per $\mathrm{d})$. The median intake of whole grains ranged from 9.4 to $48.7 \mathrm{~g} / 10 \mathrm{MJ}$ per $\mathrm{d}$ across age groups (Table 1 ). The $48 \mathrm{~g}$ DTI was not met by $71.7 \%$ of adults, nor by $72.7 \%$ of the total population aged $\geq 9$ years to which the DTI applies. A larger proportion of older Australian adults aged $\geq 51$ years ( $42.4 \%$ ) reached the $48 \mathrm{~g}$ DTI than adults aged 19-50 years $(38.4 \% ; P=<0.001)$.

Median reported whole grain intake was lowest for the age group $14-18$ years $(8.7 \mathrm{~g} / \mathrm{d})$, males $(8.6 \mathrm{~g} / \mathrm{d})$ and females $(8.9 \mathrm{~g} / \mathrm{d})$, and highest overall for the age group $\geq 71$ years $(33.7 \mathrm{~g} / \mathrm{d})$, males $(35.9 \mathrm{~g} / \mathrm{d})$ and females $(33.0 \mathrm{~g} / \mathrm{d}$; Table 1). Using absolute values, males consumed more whole grains than females. However, when whole grain intake was adjusted for energy intake, females appeared to consume relatively more whole grains than males $(29 \cdot 7 \mathrm{~g} / 10 \mathrm{MJ}$ per $\mathrm{d}$ for females, $25 \cdot 8 \mathrm{~g} / 10 \mathrm{MJ}$ per $\mathrm{d}$ for males) within all age groups $>14$ years.

\section{Whole grain consumers and non-consumers}

Among all respondents to the NNPAS, 29.1\% (30.9\% of males, $27.5 \%$ of females) did not consume any whole grains on the day of the survey. Of the whole population sampled, $28.8 \%$ of adults and $29.9 \%$ of children did not report consuming any whole grains on the day of the survey. The highest proportion of non-consumers was among males aged $14-18$ years (40.0\%), followed by females also aged 14-18 years (36.9\%). Both males and females aged $\geq 71$ years comprised the largest proportion of consumers.

Among adults who reported consuming whole grains on the day of the survey $(>0.0 \mathrm{~g}, n$ 6648), the median whole grain intake was $38.4 \mathrm{~g} / \mathrm{d}$ (interquartile range $19 \cdot 0-66.0 \mathrm{~g} / \mathrm{d}$ ) with the $48 \mathrm{~g}$ DTI not reached by $60 \cdot 3 \%$ of adult consumers of whole grains.

\section{Sources of whole grain intake}

Core foods contributed $82.4 \%$ of total whole grain intake for children and $96.3 \%$ of total whole grain intake for adults, indicating small contributions from discretionary foods. Key discretionary sources included muesli or cereal-style bars ( 43 and $46 \%$ of total whole grain intake from discretionary foods for children and adults, respectively) and corn snacks (children 35\%, adults 27\%), including buttered popcorn.

Across all foods identified as containing whole grains, the cereals and cereal products food group contributed the largest proportion to whole grain intake among children and adults. Major reported whole grain sources for children included ready-to-eat cereals (RTEC) and regular breads and bread rolls. For both children and adults, regular breads and bread rolls and RTEC were the largest contributors to whole grain intake (Table 2).

Persons consuming very low or no amounts of whole grains still appeared to consume foods from the cereals and cereal products major food group. However, this same group tended to report consuming refined versions

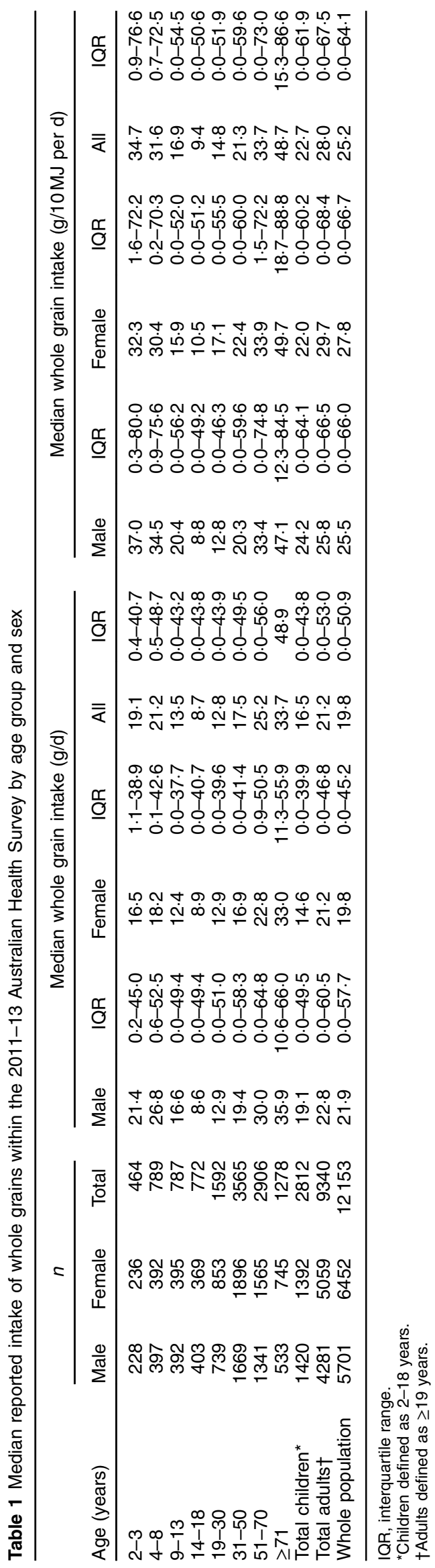


Table 2 Percentage contribution of food groups to total whole grain intake of children and adults in the 2011-13 Australian Health Survey, based on gram weight of all foods consumed

\begin{tabular}{|c|c|c|}
\hline \multirow[b]{2}{*}{ Food category } & \multicolumn{2}{|c|}{$\begin{array}{c}\text { Contribution to } \\
\text { total whole } \\
\text { grain intake }\end{array}$} \\
\hline & $\begin{array}{l}\text { Children } \\
(\%)\end{array}$ & $\begin{array}{c}\text { Adults } \\
(\%)\end{array}$ \\
\hline Cereals and cereal products ${ }^{*}$ & $84 \cdot 0$ & 89.9 \\
\hline Breakfast cereals, ready to eat $\dagger$ & $36 \cdot 3$ & 35.5 \\
\hline $\begin{array}{l}\text { Breakfast cereal, wheat based, fortified, } \\
\text { sugars } \leq 20 \mathrm{~g} / 100 \mathrm{~g} \ddagger\end{array}$ & $22 \cdot 1$ & $12 \cdot 9$ \\
\hline Breakfast cereal, wheat based & $2 \cdot 8$ & $2 \cdot 3$ \\
\hline $\begin{array}{l}\text { Breakfast cereal, mixed grain, with fruit } \\
\text { and/or nuts, fortified }\end{array}$ & $2 \cdot 5$ & $4 \cdot 3$ \\
\hline $\begin{array}{l}\text { Breakfast cereal, mixed grain, fortified, } \\
\text { sugars }>20 \mathrm{~g} / 100 \mathrm{~g}\end{array}$ & $2 \cdot 3$ & 0.3 \\
\hline $\begin{array}{l}\text { Breakfast cereal, mixed grain, fortified, } \\
\text { sugars } \leq 20 \mathrm{~g} / 100 \mathrm{~g}\end{array}$ & $2 \cdot 1$ & $1 \cdot 0$ \\
\hline $\begin{array}{l}\text { Breakfast cereal, wheat based, with fruit and/ } \\
\text { or nuts, fortified, sugars } \leq 25 \mathrm{~g} / 100 \mathrm{~g}\end{array}$ & $2 \cdot 0$ & 1.9 \\
\hline $\begin{array}{l}\text { Breakfast cereal, mixed grain, with fruit } \\
\text { and/or nuts }\end{array}$ & $1 \cdot 8$ & $11 \cdot 7$ \\
\hline $\begin{array}{l}\text { Regular breads, and bread rolls (plain/unfilled/ } \\
\text { untopped varieties) }\end{array}$ & 33.7 & $36 \cdot 4$ \\
\hline $\begin{array}{l}\text { Breads, and bread rolls, wholemeal, not } \\
\text { stated as to fortification }\end{array}$ & $13 \cdot 3$ & 8.4 \\
\hline $\begin{array}{l}\text { Breads, and bread rolls, wholemeal and } \\
\text { brown, mandatorily fortified }\end{array}$ & $9 \cdot 4$ & $14 \cdot 0$ \\
\hline $\begin{array}{l}\text { Breads, and bread rolls, mixed grain, not } \\
\text { stated as to fortification }\end{array}$ & $4 \cdot 7$ & $3 \cdot 9$ \\
\hline $\begin{array}{l}\text { Breads, and bread rolls, mixed grain, } \\
\text { mandatorily fortified }\end{array}$ & $3 \cdot 7$ & $6 \cdot 9$ \\
\hline Breakfast cereals, hot porridge style & $7 \cdot 8$ & $10 \cdot 7$ \\
\hline Porridge style, oat based & $7 \cdot 8$ & $10 \cdot 7$ \\
\hline $\begin{array}{l}\text { English-style muffins, flat breads, } \\
\text { and savoury and sweet breads }\end{array}$ & $3 \cdot 1$ & $2 \cdot 6$ \\
\hline Flat breads (e.g. pita bread), wheat based & 2.9 & $2 \cdot 3$ \\
\hline Flours and other cereal grains and starches & $2 \cdot 8$ & 4.4 \\
\hline Cereal-based products and dishes & $6 \cdot 6$ & $6 \cdot 4$ \\
\hline $\begin{array}{l}\text { Mixed dishes where cereal is the major } \\
\text { ingredient }\end{array}$ & $4 \cdot 1$ & 3.6 \\
\hline Savoury biscuits & 1.9 & $2 \cdot 1$ \\
\hline Snack foods & 4.5 & 1.2 \\
\hline Confectionery and cereal/nut/fruit/seed bars & 4.2 & $1 \cdot 7$ \\
\hline Muesli or cereal-style bars & 4.2 & 1.7 \\
\hline $\begin{array}{l}\text { Muesli and cereal-style bars, added coatings } \\
\text { or confectionery }\end{array}$ & $2 \cdot 2$ & 0.5 \\
\hline $\begin{array}{l}\text { Muesli and cereal-style bars, with fruit } \\
\text { and/or nuts }\end{array}$ & $2 \cdot 0$ & $1 \cdot 2$ \\
\hline
\end{tabular}

*Major food group.

tSub-major food group.

$\ddagger$ Minor food group.

of cereal foods. On a gram weight basis of total food consumption, mean intakes of the major food groups including cereal and cereal products, and cereal-based products and dishes, are not dissimilar among the lowest and highest groups of whole grain consumers within each age group (Table 3).

\section{Discussion}

The present study reports the whole grain intake of Australian children and adults, based on one day of dietary intake data from the 2011-13 NNPAS. It provides the most comprehensive analysis of whole grain consumption in an Australian population published to date.

The median intakes were 17 and $21 \mathrm{~g} / \mathrm{d}$ for children and adults, respectively, with approximately $30 \%$ of children and adults considered non-consumers of whole grains. After adjusting for energy intake, adult females appeared to consume more whole grains than males. The reported whole grain intake in this sample was low, with $73 \%$ of adults not meeting the recommended DTI for whole grains. The highest median daily whole grain intake reported was observed in males aged $\geq 71$ years $(35.9 \mathrm{~g} / \mathrm{d}$ ) falling below the DTI. This concurs with comparable reports from other Western countries. Mann et al. ${ }^{(18)}$ reported median intake in the UK of 13 and $20 \mathrm{~g} / \mathrm{d}$ for children and adults respectively, with 15 and $18 \%$ being non-consumers, collected through estimated $3 \mathrm{~d}$ food diaries. Median intake among US adults was lower $(10-12 \mathrm{~g} / \mathrm{d})$. Less than $1 \%$ of the US population consumed the recommended three servings ( $48 \mathrm{~g}$ ) per day and $20 \%$ of adults reported consuming no whole-grain products via $24 \mathrm{~h}$ recalls ${ }^{(20)}$. Whole grain intake in Australia appears to be greater than in France, although less than in Scandinavian countries for which data are available. In France, $55 \%$ of adults and $62 \%$ of children were identified as whole grain non-consumers based on $3 \mathrm{~d}$ dietary records. Among whole grain consumers in that population, median intakes were 5.4 and $8.1 \mathrm{~g} / \mathrm{d}$ for adults and children, respectively ${ }^{(21)}$. Comparatively, Scandinavian populations consume markedly more whole grains, with median adult intakes at 35 and $49 \mathrm{~g} / \mathrm{d}$ for Swedish females and males, and 31 and $41 \mathrm{~g} / \mathrm{d}$ for Danish females and males, respectively ${ }^{(22,23)}$. While observed intake patterns are evidently similar in the USA ${ }^{(24)}$, UK and Australia, this is a contrast with the data from Scandinavian countries, where whole-grain bread is considered a staple of the diet ${ }^{(23)}$. In addition, methods used to collect dietary intake data and define and quantify whole grain intake differ between countries. This must be considered a limitation in international comparisons of whole grain intake.

Cereals and cereal products were key contributing food groups to reported whole grain intake among children and adults in the present study. These findings concur with observations in similar population-based studies in the $\mathrm{USA}^{(24,25)}$ and $\mathrm{UK}^{(26,27)}$, where the major sources of whole-grain foods were breakfast cereals and breads for children and adults, respectively.

RTEC and plain breads and bread rolls were the main sources of reported whole grains for children and adults in the present study, becoming key foods to target for increased consumption of whole-grain foods. The highest proportion of male and female non-consumers were individuals aged 14-18 years and, not unexpectedly, this age group also had the lowest median whole grain intake per day. Comparison of consumers aged 9-18 years reporting intake of less than one serving of whole grains 
Table 3 Characteristics of participants, by age group and category of whole grain intake, and mean gram weight of food intake from four major food groups, in the 2011-13 Australian Health Survey

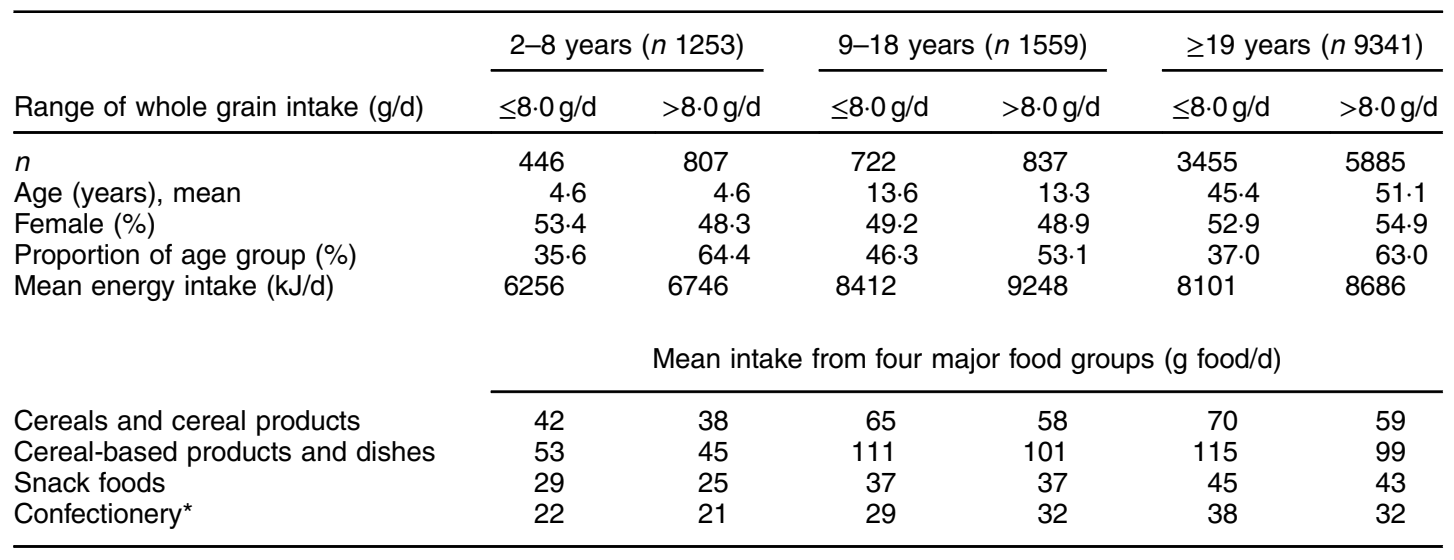

*Includes cereal/nut/fruit/seed bars.

(0-8g whole grains/d) indicates consumers within the lowest category of whole grain intake report consuming similar amounts of breads but less RTEC overall, on a gram weight basis of food intake. These consumers reported eating bread, but did not report eating whole-grain varieties of bread. They reported eating less RTEC, highlighting the importance of breakfast consumption as a contribution to overall diet quality, including meeting recommended whole grain target intakes.

This is supported by an analysis of the National Health and Nutrition Examination Survey 1999-2002, which identified that RTEC consumers had higher mean Healthy Eating Index scores for multiple food groups and higher micronutrient intakes than breakfast skippers and other breakfast consumers ${ }^{(28)}$. RTEC may be a useful vehicle for encouraging consumption of whole grains, as well as fruit and dairy foods ${ }^{(29)}$. Preferably, RTEC with limited amounts of added sugar would be encouraged. Myhre et al. ${ }^{(30)}$ investigated the importance of different meal types for the intakes of whole grains, fruits, vegetables and fish in Norwegian adults. Breakfast was the most important meal for whole grain intake within this cohort and consequently a lower intake of whole grains was observed on days when breakfast was skipped. Breakfast skipping is noticeably common among 14-18-year-old adolescents ${ }^{(29)}$ and has been associated with a lower dietary quality and adverse health outcomes; although results have been inconsistent ${ }^{(28,29)}$. This highlights implications for practice, and the potential importance of focusing on meal types to target improvements in whole grain intake ${ }^{(31)}$, while contributing to a message which is understandable and adaptable at a broader public health level.

Whole grain consumers have been characterised as having an overall healthier diet and generally healthier lifestyle habits ${ }^{(24,25,32,33)}$. Analysing intake of adult whole grain consumers in comparison with the lowest category of whole grain intakes, on a gram weight basis of food intake, indicated that the latter do report to consume foods from the breads and cereals category, but chose the refined or 'white' alternatives of whole-grain products. Encouraging this population to align its intake with the Australian Dietary Guidelines recommendations to choose mostly whole-grain and/or high-fibre varieties within the grain foods group ${ }^{(7)}$ may be a useful strategy for increasing whole grain consumption. In order to increase consumption of whole grains at a population level, concerted efforts are necessary to both decrease the proportion of low and non-consumers, by encouraging higher-quality choices within the breads and cereals food group, and increase consumption in existing consumers, focused on groups with particularly low consumption ${ }^{(34)}$.

The present study is the first to report estimates of whole grain intake within the Australian population, utilising data from the most recent national survey in Australia. The adopted method of reporting whole grain intake aligns with recent recommendations: specifically, reporting absolute grams of whole grains consumed rather than servings of intake and separating added bran and germ from calculations ${ }^{(35)}$. This contributes to international consistency in quantifying whole grain intake within epidemiological studies.

The retrospective cross-sectional design of the NNPAS lacks temporality; hence results from the current analysis cannot determine causation. Further, $24 \mathrm{~h}$ dietary recalls may not accurately reflect usual dietary intake patterns of participants. One day of dietary intake data was used, rather than adjusting intake with a second day of data gathered from a subset of participants, which would allow estimation of usual intake. The data were not weighted and hence results cannot be considered as representative of the Australian population. This limitation is partly adjusted for by the very large sample size, but it is still an important consideration ${ }^{(20)}$. Assumptions inherent to the whole grain database may have under- or overestimated whole grain intake within the present study. The database reflects likely, rather than actual composition of foods and changes in formulations cannot be accounted for. Despite these limitations, the analysis is useful in 
estimating whole grain intake at a point in time within a large Australian sample.

Target groups for communication strategies and product development of more sensorially appealing foods rich in whole grains should be adolescents/young adults (males and females aged 14-30 years). Activities for all low or nonconsumers may focus on increasing whole grain intake through breakfast consumption, and encouraging higher whole-grain choices within the breads and cereals category, which may reduce the proportion of non-consumers and increase average intake among consumers.

\section{Acknowledgements}

Acknowledgements: The authors thank Dr Marijka Batterham for statistical advice, Dr Sayne Dalton for assistance with the update of a whole grain database and Dr Elizabeth Neale for assistance with data management. Financial support: This research received no specific grant from any funding agency in the public, commercial or not-for-profit sectors. Conflict of interest: The authors of this document can confirm there are no conflicts of interest. C.J.C. was employed by the Grains and Legumes Nutrition Council at the time of this work, a not-for-profit organisation promoting grains and legume nutrition as part of a balanced diet in Australia. E.J.B. is a member of the GLNC Code of Practice for Whole Grain Ingredient Content Claims Steering Committee (voluntary role). Y.C.P. is a member of the Arnott's steering committee for children's snacks. Authorship: L.M.G., E.J.B., Y.C.P. and C.J.C. formulated research questions and designed the study. L.M.G. and E.J.B. conducted the study and completed data analysis. All authors contributed to writing the article and approving the final version for submission. Ethics of human subject participation: Not applicable.

\section{References}

1. Ye EQ, Chacko SA, Chou EL et al. (2012) Greater whole-grain intake is associated with lower risk of type 2 diabetes, cardiovascular disease, and weight gain. J Nutr 142, 1304-1313.

2. Mellen PB, Walsh TF \& Herrington DM (2008) Whole grain intake and cardiovascular disease: a meta-analysis. Nutr Metab Cardiovasc Dis 18, 283-290.

3. Aune D, Norat T, Romundstad P et al. (2013) Whole grain and refined grain consumption and the risk of type 2 diabetes: a systematic review and dose-response metaanalysis of cohort studies. Eur J Epidemiol 28, 845-858.

4. Aune D, Chan DS, Lau R et al. (2011) Dietary fibre, whole grains, and risk of colorectal cancer: systematic review and dose-response meta-analysis of prospective studies. BMJ 343, d6617.

5. Koh-Banerjee P, Franz M, Sampson L et al. (2004) Changes in whole-grain, bran, and cereal fiber consumption in relation to 8-y weight gain among men. Am J Clin Nutr 80, $1237-1245$.

6. Liu S, Willett WC, Manson JE et al. (2003) Relation between changes in intakes of dietary fiber and grain products and changes in weight and development of obesity among middle-aged women. Am J Clin Nutr 78, 920-927.

7. National Health and Medical Research Council (2013) Australian Dietary Guidelines. Canberra: NHMRC.

8. Griffiths T \& Nestel P (2006) Developing a target for daily wholegrain intake for Australians. Food Aust 58, 431-433.

9. Galea LM, Dalton SMC, Beck EJ et al. (2016) Update of a database for estimation of whole grain content of foods in Australia. J Food Compost Anal 50, 23-29.

10. Sandvik P, Kihlberg I, Lindroos AK et al. (2014) Bread consumption patterns in a Swedish national dietary survey focusing particularly on whole-grain and rye bread. Food Nutr Res 2014, 58.

11. Newby PK, Maras J, Bakun P et al. (2007) Intake of whole grains, refined grains, and cereal fiber measured with 7-d diet records and associations with risk factors for chronic disease. Am J Clin Nutr 86, 1745-1753.

12. Australian Bureau of Statistics (2013) 4363.0.55.001 Australian Health Survey: Users' Guide 2011-13. http:// www.abs.gov.au/AUSSTATS/abs@.nsf/DetailsPage/4363.0. 55.0012011-13?OpenDocument (accessed August 2015).

13. Australian Bureau of Statistics (2013) 4363.0.55.001 Australia Health Survey Users' Guide 2011-13: Sample Design and Selection. http://www.abs.gov.au/ausstats/abs@. nsf/Lookup/EAEDB8A62758B56ECA257B8D00229E80?open document (accessed June 2015).

14. National Health and Medical Research Council (2011) Nutrient Reference Values Summary Tables. Canberra: NHMRC.

15. Food Standards Australia New Zealand (2011) Australia New Zealand Food Standards Code - Standard 1.2.10 Characterising Ingredients and Components of Food. Canberra: FSANZ

16. Dalton SMC, Probst YC, Batterham MJ et al. (2014) Compilation of an Australian database of manufactured and packaged food products containing wholegrain ingredients. J Food Compost Anal 36, 24-34.

17. Australian Bureau of Statistics (2015) Australian Health Survey - Discretionary Food List, 2015 ed. Canberra: ABS.

18. Mann KD, Pearce MS, McKevith B et al. (2015) Low whole grain intake in the UK: results from the National Diet and Nutrition Survey rolling programme 2008-11. Br J Nutr 113, 1643-1651.

19. Cohen J (editor) (1988) Statistical Power Analysis for the Behavioral Sciences. New York: Routledge Academic.

20. O'Neil CE, Nicklas TA, Zanovec M et al. (2010) Whole-grain consumption is associated with diet quality and nutrient intake in adults: the National Health and Nutrition Examination Survey, 1999-2004. J Am Diet Assoc 110, 1461-1468.

21. Bellisle F, Hebel P, Colin J et al. (2014) Consumption of whole grains in French children, adolescents and adults. Br J Nutr 112, 1674-1684.

22. Kyrø C, Skeie G, Dragsted LO et al. (2011) Intake of whole grains in Scandinavia is associated with healthy lifestyle, socio-economic and dietary factors. Public Health Nutr 14, 1787-1795.

23. Kyrø C, Skeie G, Dragsted LO et al. (2012) Intake of whole grain in Scandinavia: intake, sources and compliance with new national recommendations. Scand J Public Health 40, 76-84.

24. Albertson AM, Reicks M, Joshi N et al. (2016) Whole grain consumption trends and associations with body weight measures in the United States: results from the cross sectional National Health and Nutrition Examination Survey 2001-2012. Nutr J 15, 8

25. Cleveland LE, Moshfegh AJ, Albertson AM et al. (2000) Dietary intake of whole grains. J Am Coll Nutr 19, 3 Suppl., 331S-338S. 
26. Thane CW, Jones AR, Stephen AM et al. (2007) Whole-grain intake of British young people aged 4-18 years. Br J Nutr 94, 825 .

27. Mann KD, Pearce MS, McKevith B et al. (2015) Whole grain intake and its association with intakes of other foods, nutrients and markers of health in the National Diet and Nutrition Survey rolling programme 2008-11. Br J Nutr 113, 1595-1602.

28. Deshmukh-Taskar PR, Radcliffe JD, Liu Y et al. (2010) Do breakfast skipping and breakfast type affect energy intake, nutrient intake, nutrient adequacy, and diet quality in young adults? NHANES 1999-2002. J Am Coll Nutr 29, 407-418.

29. Grieger JA \& Cobiac L (2012) Comparison of dietary intakes according to breakfast choice in Australian boys. Eur J Clin Nutr 66, 667-672.

30. Myhre JB, Loken EB, Wandel M et al. (2015) Meal types as sources for intakes of fruits, vegetables, fish and whole grains among Norwegian adults. Public Health Nutr 18, 2011-2021.
31. Holmback I, Ericson U, Gullberg B et al. (2009) Five meal patterns are differently associated with nutrient intakes, lifestyle factors and energy misreporting in a sub-sample of the Malmo Diet and Cancer cohort. Food Nutr Res 2009, 53.

32. O'Neil CE, Nicklas TA, Zanovec M et al. (2011) Consumption of whole grains is associated with improved diet quality and nutrient intake in children and adolescents: the National Health and Nutrition Examination Survey 1999-2004. Public Health Nutr 14, 347-355.

33. Lang R, Thane CW, Bolton-Smith C et al. (2003) Consumption of whole-grain foods by British adults: findings from further analysis of two national dietary surveys. Public Health Nutr 6, 479-484.

34. Lang R \& Jebb SA (2003) Who consumes whole grains, and how much? Proc Nutr Soc 62, 123-127.

35. Ross AB, Kristensen M, Seal CJ et al. (2015) Recommendations for reporting whole-grain intake in observational and intervention studies. Am J Clin Nutr 101, 903-907. 